\title{
Conversation Analysis and Second Language Pedagogy: A Guide for ESL/EFL Teachers
}

Jean Wong and Hansun Zhang Waring. New York: Routledge. 2010. Pp. vii + 304.

Conversation Analysis and Second Language Pedagogy locates itself at the nexus of research and practice, connecting the findings of conversation analysis (CA) to language teaching. In one sense, the text contributes to an existing, growing body of research that links CA to second language (L2) classroom interaction (e.g. Markee, 2000; Mori, 2002; Seedhouse, 2004; Waring, 2008). However, unlike most work in this vein, the authors are not attempting to describe verbal exchanges that occur in the L2 classroom. That is, rather than use CA to better understand how teachers and students talk, Wong and Waring aim to proffer CA as a way to teach talk. Indeed, this book specifically reaches out to ESL/EFL teachers tackling the task of improving their students' oral proficiency. In addition to explicating basic tenets of CA findings, each chapter teems with classroom activities designed to get students speaking and analyzing talk. Thus, as the organization of the book demonstrates, the thrust of the text is twofold: (1) to introduce CA to ESL/EFL teachers, and (2) to provide them with CA-informed speaking activities for use in their classrooms.

As stated in the Preface, the book is organized into three parts. The writers begin by arguing for CA's place in communicative language teaching (CLT), particularly with respect to interactional competence, defined as "the ability to use verbal and non-verbal resources for participating in exchanges" (p. 7). They note that "Conversation analysis delivers the stuff that interactional competence is made of, i.e., interactional practices" (p. 8). Wong and Waring then present a model of interactional practices, which represents graphically the conversational system. The model consists of turn-taking practices, from which sequential practices are constructed, which in turn build to form overall structuring practices. Repair practices are invoked if a breakdown of communication occurs during a turn or sequence of turns. The second and largest part of the book systematically considers the components of the model. An analysis of each component, illustrated through transcripts of actual talk, is accompanied by speaking activities intended to give teachers the opportunity to consider pedagogical applications of the component in question. The final section reviews, through the lens of CA, common instructional practices that may promote or suppress an atmosphere that leads to learning in the L2 language classroom. Each chapter also commences with pre-reading questions, followed by a short chapter overview. The authors then present the chapter's topics, accompanied by transcripts and tasks, which ask readers to either analyze spates of talk in the transcript, reflect on their own conversational practices, or devise ways to teach the pertinent features. The chapters subsequently include two types of activities designed for teachers to use in their own ESL/EFL classrooms: awareness-raising activities, which encourage language learners to think about how the topics at hand function in the talk in which they engage, and practicing activities, which afford students the opportunity to consciously utilize the spotlighted interactional features. Tasks are interspersed throughout the chapter sections, in which readers are invited to elaborate on, challenge, or connect material to their own observations or speech. Each chapter concludes with a summary, definitions of key terms, post-reading questions, and suggestions for further reading.

The chapter-by-chapter organization proceeds from the bottom of the model upwards, much like the bottom-up approach of CA itself. The first chapter establishes the importance of speaking for L2 language learners, noting that through talk, a language is learned. Yet, few texts 
aimed at training L2 language instructors give many details concerning the structure of conversation, or talk-in-interaction. From the outset, the authors make it clear that the book attempts to address this perceived gap through introducing CA findings to teachers. After a brief description of CA data collection techniques, transcription, and analytic techniques, the authors discuss key concepts that inform the rest of the book. They note that the Hymesian notion of communicative competence, or a speaker's ability to use the target language to interact effectively, is a goal of communicative language teaching. As noted by Wong and Waring, Celce-Murcia (2007) has revised the model of communicative competence to include interactional competence, the ability to effectively use syntactic, semantic, and lexical resources when interacting. They also claim that CA can deepen our understanding of interactional competence through illuminating the practices that constitute talk-in-interaction.

Chapter 2 explicates turn-taking practices, which are embedded in most other components of conversation. Despite its central place in their model, Wong and Waring note that very few pedagogical materials address the turn-taking system. Yet, they argue, there is no interaction without turns (p. 15). In offering a conversational-analytic account of turn taking, the writers delineate two components: turn construction and turn allocation. They then analyze the ways turns are constructed, showing ways in which interlocutors can determine the possible completion of turn in order to take the floor. The chapter also shows the resources available for a speaker to construct a multi-unit turn. The next section addresses the ways in which speakers know when to begin or end talk, a conundrum for many L2 learners. The rules that function at a possible transition place are explicated, and various techniques for initiating a turn, overlapping others' speech, or continuing a turn are shown.

Turns and talk combine to form conversational sequences, which are the focus of Chapters 3 and 4. Indeed, as the authors remark, pedagogical materials surrounding this topic abound. Few, however, engage in the fine-grained analysis of sequences that CA affords, which can in turn provide language learners with vivid description of how talk unfolds. Such an understanding, Wong and Waring claim, can help students learn what to say when and possibly circumvent situations of cross-cultural miscommunication. Chapter 3 addresses shorter spates of talk. It first discusses sequences that occur in any type of exchange, showing that they are constructed from the adjacency pair, in which one speaker's turn is responded to by another speaker's turn. The chapter then moves from generic sequences to specific ones, analyzing the structures of, for example, compliments, announcements, invitations, and complaints. The numerous activities on generic and type-specific sequences, which accompany the detailed explanations and transcripts, give teachers instructional materials for use in their ESL/EFL classrooms. Chapter 4 moves from adjacency-pair-based analysis to looking at the larger sequential elements of topic management and story-telling. In the first section, the authors trace the path of topic development, examining ways that speakers initiate, develop, and shift topics, illustrating and highlighting each element with examples from actual talk. The text then delves into story-telling practices, again using authentic conversation to show how speakers launch and recount stories, both in single-party story-telling and in multi-party story collaborations. In the awareness-raising and practicing activities, particular attention is paid to cross-cultural differences in story-telling. Readers are also invited to consider how a CA analysis of storytelling may complicate or complement traditional ESL textbook material on the same topic. 
Chapters 5 and 6 center on overall structuring practices, the third component of the model. The fifth chapter carefully considers conversation openings in the context of telephone talk. Since many language learners report difficulty with conversing on the phone, such a detailed analysis of the core sequences of telephone exchanges is very helpful for ESL/EFL instructors. Pedagogical tasks invite teachers and learners to explore cultural variations in telephone openings, and ask students to role-play as interlocutors speaking on the phone. The sixth chapter explores in-depth the complex phenomenon of conversational closings. As the authors note, knowing how to end a conversation is a crucial element of interactional competence. Yet, many scripted dialogues in ESL/EFL textbooks do not accurately represent how conversational closings actually take place. In this portion of the text, the authors explore basic closings, as well as types of preclosings, such as announcement sequences, lesson sequences, and solicitude sequences. Helpful pedagogical tasks include simulating a cocktail party, during which interlocutors hold discussions that they must conclude at the sound of a warning bell.

Interlocutors remedy communication breakdowns through repair practices, an important tool for successful interaction and the last component of the model. These practices are considered in the seventh chapter. After an explanation of the components of repair practices, various types of repair are depicted and analyzed in transcripts. Each type is closely examined in authentic talk to determine how it is initiated and either resolved or abandoned. As the authors remark, the pervasive use of repair amongst both L1 and L2 speakers can be liberating for ESL/EFL learners, who may have previously viewed the need for repair as exclusively a property of L2 talk.

The final chapter, like the preceding sections, links CA to ESL/EFL pedagogy. In lieu of a focus on a specific interactional practice as in the other chapters, Chapter 8 considers ways in which CA can inform three instructional practices in the classroom: (1) repair practices (otherwise known as corrective feedback), (2) task design, and (3) management of participation. The authors review recent conversation analytic research that has been carried out in the L2 classroom on these topics, noting the unique contributions that CA has made to deepening our understanding of discourse patterns in the L2 classroom in both teacher-student and studentstudent interactions. They conclude the chapter with suggestions for rethinking policies concerning the three aforementioned instructional practices in light of CA findings. These recommendations all point to the importance of minding the details of talk. For example, when designing tasks, teachers must focus on more than just the overarching structure of the task; they must also consider the turn- or sequential-level knowledge the student needs to successfully complete the assignment. Wong and Waring end the text with the acknowledgement that "CA research has generated more questions than it has provided answers" (p. 279), effectively issuing a call for further research on the fruitful connections researchers can make between CA and L2 pedagogy.

This text is a succinct, albeit dense, introduction to CA for language teachers, and as such, is informative. By understanding a language's interworkings in intricate detail, a teacher's ability to teach the language will almost certainly be strengthened. The teacher may also heighten her awareness concerning the ways in which classroom talk may encourage or hinder learning. The breadth and depth of the topics, coupled with the clear examples from authentic transcripts used to illustrate the points, make this book a helpful introduction for teachers about 
the basic tenets of CA. The extremely useful model of interactional practices summarizes the conversational system in a concise manner. The systematic elaboration of each component of the model reinforces the argument that the different practices within the model inform and build upon one another. By the conclusion of the text, the reader has a deep understanding of how talkin-interaction works, both in parts and as a whole.

Perhaps much more importantly, Wong and Waring make a unique contribution to the field of L2 pedagogy. Until now, CA has largely remained a framework used by and shared with other researchers in the social sciences. It has been utilized to elucidate verbal and non-verbal exchanges in the classroom, and has proven to be particularly useful for those studying the L2 classroom (e.g. Hellermann, 2008; Mori, 2002, 2004; Waring, 2008, 2009). Through looking at the microstructure of the language, the authors-like the researchers whose work precede this book-demonstrate that there is much to be learned, and much that can be taught at the turn-byturn level.

In envisioning teachers - rather than researchers - as part of the target audience, this text moves CA to the forefront of L2 instruction. By lending its findings for direct use in pedagogical activities, the authors demonstrate that CA can indeed be taught directly to L2 learners. The activities themselves are varied, and will aid students both in thinking about how the conversational system operates, and in practicing their oral skills. They can also be adapted to learners of all levels, demonstrating that using CA in the classroom need not be reserved for more advanced learners. To be sure, teachers and students alike would have to get used to CA terms and transcripts; perhaps it would be useful to present simplified versions of transcripts, and reduce the number of terms necessary for talking about the language. Nevertheless, as this book shows so well, CA can be helpful for researchers, teachers, and language learners alike.

\section{CATHERINE DIFELICE BOX}

Teachers College, Columbia University

\section{REFERENCES}

Hellermann, J. (2008). Social actions for classroom language learning. Clevedon, UK: Multilingual Matters.

Markee, N. (2000). Conversation analysis. New York: Routledge.

Mori, J. (2002). Task design, plan, and development of talk-in-interaction: An analysis of a small group activity in a Japanese language classroom. Applied Linguistics, 23, 323-347.

Mori, J. (2004). Negotiating sequential boundaries and learning opportunities: A case from the Japanese language classroom. Modern Language Journal, 88, 536-550.

Seedhouse, P. (2004). The interactional architecture of the language classroom: A conversation analysis perspective. Malden, MA: Blackwell.

Waring, H. Z. (2008). Using explicit positive assessment in the language classroom: IRF, feedback and learning opportunities. Modern Language Journal, 92, 577-594.

Waring, H. Z. (2009). Moving out of IRF (initiation-response-feedback): A single case analysis. 
Teachers College, Columbia University Working Papers in TESOL \& Applied Linguistics, Vol. 11, No. 1, pp. 67-71

Book Review

Language Learning, 59, 796-824. 